\title{
Conditional Cash Transfers: Expanding Higher Education through Social and Economic Support in Pakistan
}

\author{
Barkat Ullah Khan ${ }^{1 *}$, Syed Nadir Ali Shah'1, Rabia Gul ${ }^{2}$ \\ ${ }^{1}$ School of Public Affairs, University of Science and Technology of China, Hefei, China \\ ${ }^{2}$ School of Management, Hefei University of Technology, Hefei, China \\ Email: ^barkatbnu@gmail.com
}

How to cite this paper: Khan, B.U., Shah, S.N.A. and Gul, R. (2020) Conditional Cash Transfers: Expanding Higher Education through Social and Economic Support in Pakistan. Open Journal of Social Sciences, 8, 200-216.

https://doi.org/10.4236/jss.2020.81014

Received: December 25, 2019

Accepted: January 11, 2020

Published: January 14, 2020

Copyright $\odot 2020$ by author(s) and Scientific Research Publishing Inc. This work is licensed under the Creative Commons Attribution International License (CC BY 4.0).

http://creativecommons.org/licenses/by/4.0/

\begin{abstract}
This study was motivated by the initiatives of the Higher Education Commission (HEC) of Pakistan that provides various conditional cash transfers (CCTs) to youth education in the less developed areas of the country. The CCTs are given to youth in the shape of HEC Need-Based Scholarships (HEC-NBS) and the Prime Minister's Fee Reimbursement Scheme (PMFRS). This study investigates the impact of the CCTs on the educational performance of the students in the under-developed areas of Pakistan. Data were gathered through self-administered questionnaires from the students who were awardees of the scholarships. A total of 350 responses were used for the final analysis. A statistical package for social sciences (SPSS) version 25 was used to get the data analyzed. It was found that the two CCTs (HEC-NBS and PMFRS) substantially affect the educational performance of the students. The PMFRS was the most dominant predictor of the students' performance indicating a high tangible source of students' motivation. This study helps in both theoretical and practical spectrums. It practically helps expand the higher education to every nook of the country as well as light the policy-making outlines to sustain the CCTs for the better future of higher education in Pakistan.
\end{abstract}

\section{Keywords}

Conditional Cash Transfer, Youth Education, HEC Need-Based Scholarships, Prime Minister's Youth Laptop Scheme, Pakistan

\section{Introduction}

The quality education is an essential element for the educational development of any country because only high standard education can help achieve the millen- 
nium goals. Baum, Ma and Payea [1] found that a need-based scholarship is a viable tool for attainment and promotion of higher education and therefore various countries allocate huge sums of money for this purpose. Provision of the scholarships is equally acknowledged and given in both developed and underdeveloped nations [2]. The low or no access of common citizens to high education is always due to poverty and other financial issues that are faced especially in low-income countries [3] [4]. To address such issues, various schemes and structures were adopted under the umbrella of social investments such as conditional cash transfer (CCT). CCTs refer to the social facilitation that is provided by various organizations like governments and other institutions/bodies.

The CCTs that were initiated in 1990 were named as "Home Grown" in Brazil and Mexico. These CCTs were granted with a view to help the dejected and the poor sections of their society and thus enable them to go with the mainstream in getting a higher education [5]. These plans aimed to reduce the poverty rate and assist the deprived people to attain higher education and keep them healthy. This model was borrowed and commenced by the governments in many countries after its successful impacts on the local populace. World Bank and Inter-American Development Bank (IDB) borrowed the idea and initiated the CCTs in various under-developed areas [6] [7] [8].

The Government of Pakistan also adopted such programs of CCTs to facilitate various divisions particularly the education sector. Pakistan is among the emerging economies and is making ceaseless efforts to follow the successful schemes of developed countries to promote its higher education in all of its areas [9]. Education represents the intellectual journey of any country and therefore the Pakistani government is striving hard to equip its human resources (Youth) who can ensure the bright future of Pakistan [10] [11]. It is also a fact that many of the youth are unable to bear the costs of higher education and it is like a daydream for the sons of the have nots [10]. To this end, the government of Pakis$\tan$ started various schemes to remove the hurdles in higher education such as the "Higher Education Commission (HEC) need-based scholarship". This program was launched with the aim to aid the children of very poor class and flourishing regions in achieving the education [11]. Another scheme that was started with a view to developing "technology culture" in Pakistan, was called the "Prime Minister's Youth Laptop" scheme [12]. The key motives of this scheme are to improve information and communication technology, give the deprived student with quality education and help the students get the latest learning tools without being restricted by their lack of resources.

Past studies on CCTs reveal that, in general, these plans have positive impacts on education; for example, they help increase students' enrollment, improves presence, reduces dropouts from university etc. and yields in health-related positive results such as inoculations and regular check-ups [7]. Besides providing multiple benefits, there is a dearth of studies that incorporate the CCTs in an organized way and thus exploring the impact of the CCT programs on the educational wellbeing of youth. There are only a few studies elucidating the CCTs 
like Manley and Slavchevska [13] who worked as a meta-analysis to understand the effect of CCT programs on health status. Therefore, the researchers felt a dire need to give input to the literature on CCTs and thus evidencing the phenomenon in a developing country, Pakistan.

It is worth mentionable that the HEC need based scholarship was started in the start of 2019 with the aim to provide assistance to the talented students who are the apples of poor families and disadvantaged class. They were incapable to meet their educational expenses, so they were made eligible for the scholarships. To this end, HEC Pakistan has established a special online portal as well as directed all the universities in the less-developed areas to register deserving students for the scholarships. Similarly, the Prime Minister of Pakistan initiated a huge package (around Rs Billion) for six schemes including the prime minister laptop scheme in Pakistan. This program has a target "to encourage an energetic and harmonious Pakistani youth with strong spiritual and moral values".

This study focuses on the development of CCT as a social investment as well as an economic instrument that has many implications for the students and researchers in Pakistan. To this end, the study will analyze the short term and long term progress and will find the hurdles, if any, in the development of CCTs in Pakistan. The study is the first one exploring the impact of CCTs (HEC Need-Based Scholarships and Prime Minister's Fee Reimbursement Scheme) on students' academic achievement and promotion. Such type of study has not so far conducted in the Asian region or in the context of developing countries like Pakistan. This study will not only helpful for the needy people to get their higher education but also will achieve the targets of education enrollments in the higher education institutions of Pakistan. To sum up, the study aims to explore the achievement status of Short term and long term objectives of HEC need-based scholarships and the Prime Minister's Youth Laptop Program on students' educational performance.

\section{Literature Review}

\subsection{Conditional Cash Transfers (CCTs) and Educational Accomplishment}

Conditional cash transfers (CCTs) were developed as an innovative plan in the decade of the 1990s as an element of social protection actions in order to support the poor and deprived people of the country [14] who survive under the poverty rank. At first, unconditional cash transfers were investigational but at the present time, conditional cash transfer (CCT) plans are broadly studied. It is apparent from the name of CCT that such financial gains are extended on the condition that beneficiaries will ensure the fulfillment of particular terms and conditions [15].

In accordance with the Benhassine et al. [16], CCTs have been involved in carrying the alterations and transformations in the lives of the citizens. Cash transfers are considered as not merely aiding the deprived individuals to reduce 
their poverty but it is also a possible instrument of capability constructing of the susceptible people primarily children in the family with having long term effects. According to De La O [17], the CCTs are aimed at providing twofold advantages of aiding; first to attain enrolments in educational institutes; and secondly, visiting healthcare centers for protecting youth/children thus reducing the banes of poverty experienced by the deprived. Several studies have demonstrated that CCTs have attained university or school enrolment and precautionary healthcare goals. Others see that CCTs have facilitated children who belong to the poor households to come into the citizenship condition by getting listed with the state. Baird, Ferreira, Özler, and Woolcock [18] argued that situations linked with CCT in comparison with children have decreased the proportion of children's marriages.

Some researchers highlighted that the help which is given in the form of cash for the welfare of children is not sufficient. Poor families are unable to fulfill their requirements and basic desires neither from the unconditional nor from conditional aid; so they ultimately involve their children in the workforce [19]. Dependent upon the observation of various CCT plans in Latin America, $\mathrm{Zi}$ bagwe et al. [20] discussed that such cash schemes have been incapable to create special outcomes for poor youth. Poor youth who obtain conditional healthcare help is lower in their body weight than those who get unconditional aid, as parents keep them under-nourished in order to make certain the transfer of cash funding to them. Furthermore, while CCTs can be an assurance for the schooling of poor children but it has been incapable to diminish the child labor in a developing country such as Pakistan.

De Brauw and Hoddinott [21] have stated that CCTs aid poor families to relocate money in place of in-kind transfer. In most cases, such schemes are objected to socially disadvantage groups, for instance, women or poor people. The CCT plan is quickly becoming a main strategic tool utilized by emerging nations to decrease poverty and to boost investment in human capital. Many developed nations have shifted swiftly to CCTs to encourage families to send their children to educational institutes [22]. These CCT programs relocate earning to a family in replace for the family sending their youth to learn. Some of this attempt appears to be mistaken because the poor generally experience temporary earning flows that might make them show poorer some months and wealthier in others. In developing countries like Pakistan, it can be valuable for authorities to set up which families fulfill the criteria on the basis of earnings and which do not, and such attempts bring about ethical risk issues in which family may take on actions that lower their gained earnings but boost their possibility of receiving the government transfer [23]. There are many benefits of utilizing geographic goals in populations where poverty is almost widespread. In developed regions such as urban areas, targeting people educational level might be less costly and will be a better substitute for stable returns than is existing income. In Pakistan, CCT plans are also proficient in increasing students' enrollment in public educational institutes [24]. Another plan in Pakistan is supported by NGOs in order to build 
institutes by paying financial support for every girl enrolled. The plan achieved important development by increasing the enrollment rate of young girls and closing the enrollment gap with young boys [25].

There is a strong verification that CCT programs have a noteworthy impact on rising university admission rates, particularly for getting a higher education. The anticipated impacts vary from a seven to nine percent rise for girls and a three to five percent increase for boys in secondary school [17]. CCTs also reduce students' dropout rates. Dubois, De Janvry, and Sadoulet [26] have observed a 0.9 percent rise in retention rates for program beneficiary over non-beneficiary. Furthermore, if a less capable student returns to university due to the CCT plan, partiality towards the lower education attainment scores of these students would appear in any study exploring grade retention levels.

CCT schemes can impact students' accomplishments by various potential means. A study has observed that student attendance rises as a result of the CCT plan [27]. If the educational institute is of adequate class, then there ought to be a direct impact of attendance on the educational performance of young students. In addition, the CCTs raise disposable revenue which may impact the cognitive attainment of university students. This might be fulfilled by means of direct investments such as course books that give a more encouraging home setting [28] or by influencing the attitude of parenting by easing material hardship and parental anxiety [29].

High family earnings may decrease the stress on youth to work outside their home which reduces the students' university attendance or also affects the completion of their home assignments and projects in time. Certainly, the study has exposed that CCT schemes have decreased child labor force [30] and enhanced homework time, a transformation that may recover student's university attainment. However, conditional cash transfers (CCT) can also impact the volume of the class and work, which might not positively impact the students' performance. In fact, without supply-side involvement, enhanced students' enrollment increases the size of the class. Although practical proof is uncertain, some studies in emerging nations have found a negative impact of class volume on students' grades [31]

Educational institutes and professors might be challenged by handling both formerly enrolled students and a new enroller who is required to join the wagon. If the ability of the educator and instructional alteration is insufficient, this variety can indirectly impact the learning and exam grades of the students. Moreover, newly enrolled students with lesser aptitude or negative behavior toward studies can negatively impact the other students of the same course. A study from mostly emerged nations has shown that students are influenced by peer attainment [14] because of the CCT program leads to a higher learning environment.

\subsection{State of Education in Pakistan and CCTs}

According to Memon and Awan [32], the factors i.e. "access to" education and 
"access in" education is entirely two different aspects. "Access to" implies to have the right of entry to the educational institutes, admission processes and so on. "Access in" implies the value of education and knowledge, and the degree of involvement in university life. As per the investigations, Pakistan's development in higher education and admissions in the formal learning structure has been flawed by constant, overlying dissimilarities in access to, and access in educational institutes [33]. The low access to education in Pakistan is one of the globe's lowest achievement levels for basic education. The awful degrees of people investing in education under succeeding control consider the weak quality of education, poor educational results as well as insufficient infrastructure.

Pakistan is a symbol of several global obligations about the objective of worldwide education such as education for all, Millennium Development Goals (MDG) and Sustainable Development Goals (SDGs) [34]. These obligations have been integrated into Pakistan's national program. The law of Pakistan gives a right to free education and acknowledges that it is the government's responsibility to give the right to Pakistani citizens. Pakistan's constitutional amendment 18 (2010) describes that the state shall give free of cost and obligatory education to all people in such a way as established by the Pakistani law [35]. On the other hand, increasing university admissions all the way through improved access to education for over ten years has barely enhanced the dilemma of the usual citizen. Complete poverty exists alongside community stratification and extended differences between the wealthy and deprived people. Redundancy rates also stay greater with the educated comprising a huge percentage of the unemployed people. While the malfunction of the education structure alone cannot be held responsible, it is crucial to recognize that some of the issues are overstated concerning the educational prospects. Pakistan's national survey (1998) states that any person who is ten years or elder and is able to read out a newspaper and write down a simple note in any language is educated.

Pakistan has dedicated to the Education for all (EFA) objectives that include attaining a fifty percent development in adult education rates by the year 2018, alongside with the reasonable access of education for everyone [33]. On the other hand, the nation constantly lags behind in its educational goals. The average development in the education level is approximately 1.3 percent per annum between the year 2005 and 2018. Differences in education ranks are severe across various regions in Pakistan between more and less emerged areas, comprising both urban and rural. The education rate for ten years of age and above is around twenty-five percent lesser in rural regions in contrast to the urban regions. The comparatively greater illiteracy levels for susceptible kinds, for example, women and rural inhabitants signify the strong lack of education that motivates the CCTs. These outlines cause significant challenges regarding how people reflect higher education from a human growth perspective, how education is evaluated, and what strategies are required in order to increase the educational results and procedures with the passage of time [36].

People mainly learn during their youth and they study not only through 
course books or educational institutes but also by means of practical experience either by adopting capabilities around the house or doing any job. These experiences arise under the wide shade of education. The human growth perception views education as one of the major techniques for increasing the skills and abilities of youth, liberalism and alternatives [37]. However, the educational enrolment levels in Pakistan have increased to some extent over the last decade. The dropout rate of students is also higher in Pakistan. Education has to be completed precisely in order to facilitate the youth to make accurate selections for the future [37]. The research explores the CCTs' relevance to the higher education growth in Pakistan with the purpose of obtaining its significance towards preparing youth for resourceful employment and commitment.

It is an immense need of the hour to emphasize on offering a high quality of education rather than only focusing on the quantity in Pakistan [38]. To this end, Pakistan has to provide and strengthen CCT programs in formal education in addition to improving and incorporating practical education and occupational training in the current structure of education. Especially, the CCTs have to streamline where there is a lack of producing efficient opportunities for youth service and appointments. The total enrollment in primary education is even lesser than the low earning countries of the South Asian and the Sub-Saharan Africa States in Pakistan. The conceptual model of this study is presented in Figure 1.

\section{Research Methodology}

\subsection{Population and Sampling}

The population of this research comprised of the universities' students who are awardees of the CCTs, that is, either received/receiving the HEC need-based scholarship or got/getting Prime Minister's Fee Reimbursement Scheme (PMFRS). The sample for the study was taken from four districts in the Khyber Pakhtunkhwa (KP) province, Pakistan. Only those districts (Bannu, Karak, Lakki Marwat, and Dera Ismail Khan) were selected for data collection that was in

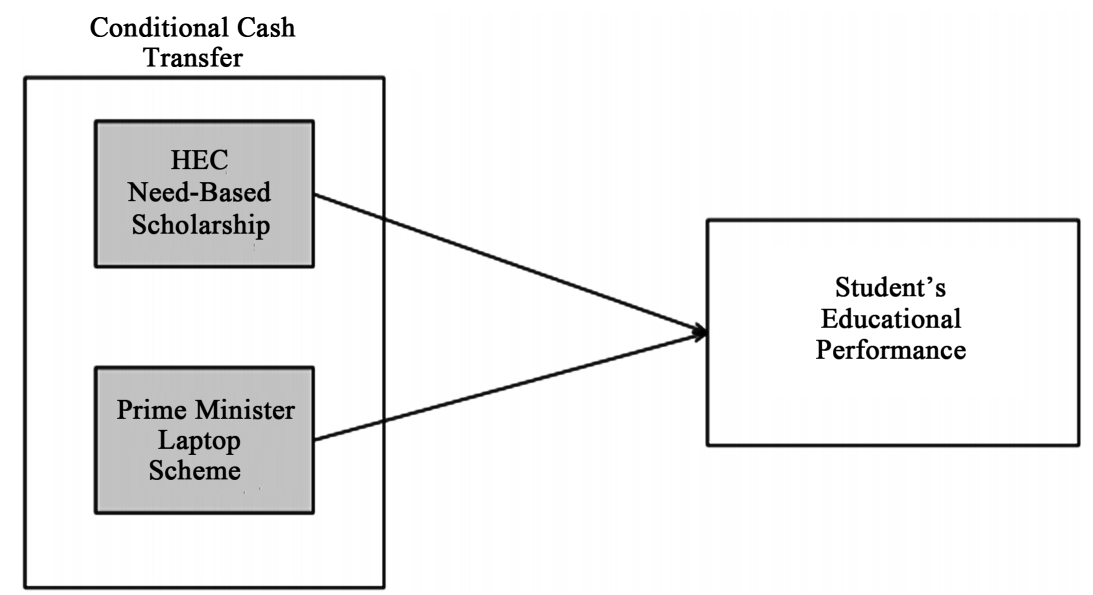

Figure 1. Theoretical framework. 
the less developed areas and was duly eligible for the PMFRS. In this respect, a self-administered questionnaire, that was adapted from previous studies, was used for data collection. More specifically, using a purposive sampling technique, a total of 300 questionnaires were distributed in the higher education institutions of the four districts. The researchers personally visited the said districts and administered the questionnaire carefully and ethically. They were present at the moment for clarifying any query/difficulty where the students responded in a free atmosphere. In a total of 300 respondents, $54 \%$ were female and $46 \%$ were male students. The sample consisted of $28 \%$ of students below 20 years and $72 \%$ of students were aged in-between $21-23$ years. In the sample of 300 participants, $42 \%$ were bachelor students and $58 \%$ were from masters and above students.

\subsection{Measures}

After collecting the required data from respondents, the data were analyzed through SPSS version 25. The performance of the students is measured through their CGPA in different semesters because it has been utilized in several past studies [39]. Moreover, it is the main measure of students' educational performance. The success of the Prime Minister's Laptop Scheme has been examined with the help of a fourteen items' scale which attempted to determine the use of laptops after receiving it. The question items have been adopted from many previous studies in order to have a valid instrument. Lastly, the success of the Higher Education Commission Need-Based Scholarship has been evaluated by seven questions. The instrument scale used for HEC need-based scholarship and Prime Minster laptop scheme is 5 points Likert scale which starts from 1 to 5 strongly disagrees to strongly agree.

\section{Results}

\subsection{Reliability of the Scale}

To test the reliability of the scale we calculated Cronbach Alfa value of each construct in SPSS. If the Cronbach Alfa value is greater than $\mathrm{a}=0.07$ it is acceptable in social sciences study and data is valid overall. The reliability of our data was good as the results show the Cronbach Alfa value of HEC Need-Based Scholarship (NBS) 0.852 and Prime Minster Laptop Scheme (PLS) 0.799 which is greater than the standard level.

\subsection{Descriptive Statistics Analysis}

Table 1 shows the minimum, maximum, and mean values of data. In the Table, the minimum values, maximum values, mean values and the standard deviation of predictors and dependent variables have been shown. The number of observations for each variable is 300 . Standard deviation and the extreme values (minimum in comparison to maximum value) give the idea about the dispersion of the values of a variable from its mean value. The Minimum value of the 
Table 1. Minimum, maximum and descriptive statistics.

\begin{tabular}{cccccc}
\hline & N & Minimum & Maximum & Mean & Std. Deviation \\
\hline HEC Need Based Scholarship & 300 & 10 & 20 & 12.27 & 0.927 \\
Prime Minister Laptop Scheme & 300 & 15 & 30 & 16.72 & 0.950 \\
Students' Academic Performance & 300 & 5 & 10 & 6.25 & 0.485 \\
Valid N & 300 & & & & \\
\hline
\end{tabular}

HEC-Need-Based scholarship is 10 while the maximum value is 20 . Similarly, the Mean value is 12.27 with a standard deviation of 0.927 . The Minimum value of the Prime Minister Laptop Scheme is 15 while the maximum value is 30 . Moreover, its Mean value is 16.72 with a standard deviation of 0.950 . The Minimum value of the students' academic performance is 5 while the maximum value is 10 . The Mean value is 6.25 with a standard deviation of 0.485 .

\subsection{Correlation Test}

Table 2 shows that all the variables have a positive correlational relationship with each other and the result is significant and positive. The correlation values signify that there are positive correlations between the predictor variables and are not so high to make a multi-collinearity issue.

\subsection{Frequency Distribution Analysis}

To check the productivity and achievement of Government laptop scheme in the short run, different questions have been asked. "Time you were used to spending before getting a laptop on watching movies" and "Time you spend on your laptop which you got from Government Laptop Scheme, for Watching movies". The results show that most of the students used spending their time (1 hour or less) on watching movies before the Government Laptop Program. The result of the second question shows an increase in the usage of laptops by the students from $1-2$ hours and $2-4$ hours for watching movies after getting the laptop through the Government Laptop Program. This increase leads to the non-productive use of the laptop for the short term as the majority of the students are using laptops for entertainment purposes hence ignoring the productive purposes.

"Time that you were spending before getting a laptop for playing games" and "Time you spend on your laptop which you got from Government Laptop Scheme for playing games". Table 4 "SBPG" shows that most students as $72.7 \%$ before getting the laptop through the Government Laptop Program used to spend their 1 hour or less on playing games. However, Table 5 "SAPG" shows an increase in the usage of laptops by the students after getting the laptop through the Government Laptop Program as now the students were using their laptops 2 - 4 hours for playing games. This increase leads to the non-productive use of the laptop for the short term as most students are using laptops for entertainment purposes, not for a productive or positive purpose. 
Table 2. Pearson correlation.

\begin{tabular}{cccc}
\hline Need-Based Scholarship & 1 & & \\
Prime Minister Laptop Scheme & $0.350^{\star *}$ & 1 & \\
Student Academic Performance & $0.248^{* *}$ & $0.425^{\star *}$ & 1 \\
\hline
\end{tabular}

Table 5 and Table 6 depict the results related to the questions "Time you were used to spending before getting laptop for making your presentations and assignments i.e. for your study related work" and "Time you spend on your laptop which you got from Government Laptop Scheme for making your presentations and assignments i.e. for your study related work". Table 5 shows that a large number of students (37.7\%) were using time, for 1 hour or less, for making their presentations and assignments before getting the laptop through the Government Laptop Program. Our results confirm that a huge increase occurred in the usage of laptops by the students i.e., 6 hours or above (from 24.0\%) and 2 - 4 hours (from 17.3) for making their presentations and assignments after getting the laptop through the Government Laptop Program. This increase leads to a wonderful productive use of a laptop for the short term as most of the students reported that they are using laptops for productive and positive purposes. The most positive use of laptops given by the Government to students has been examined through this analysis.

"Time you were used to spending before getting a laptop on social media" and "Time you spend on your laptop which you got from Government Laptop Scheme, for social media". The results show that most students before getting the laptop through the Government Laptop Program used to spend 1 hour or less (1 - 2 hours) on social media, yet an increase was reported in the usage of laptop by the students after getting the laptop through the Government Laptop Program i.e., 4 - 6 hours and 6 hours or above for social media. This was attributable to the fact the most of the students tend to use laptops for their entertainment purposes.

The overall analysis, as depicted by Table 3 and Table 4 elucidates that the students have increased their tendencies towards achieving their goals form unproductive usages of the schemes towards more positive and goal-oriented uses of the government laptops.

Table 5 specifically explains the students' time schedule and usages of laptops for academic purposes. The students need different sorts of presentations and assignments to be completed in a given time. The needy students who were awardees of the prime minister lap top schemes opined whose results depict that the majority of the students (about 28\%) spend $2-4$ hours on the laptops for making presentations and assignments.

\subsection{Regression Analysis}

\subsubsection{HEC Need-Based Scholarship and Students' Education Performance in Short and Long Term Results}

Table 6 mentions that there is a positive and significant relationship between the 
Table 3. Students' time spending on laptop for watching movies.

\begin{tabular}{cccccc}
\hline & Frequency & Percent & Valid Percent & Cumulative Percent \\
\hline & 1 hour or less & 52 & 17.3 & 17.3 & 17.3 \\
& $1-2$ hours & 113 & 37.7 & 37.7 & 55.0 \\
Valid & $2-4$ hours & 126 & 42.0 & 42.0 & 97.0 \\
& $4-6$ hours & 3 & 1.0 & 1.0 & 98.0 \\
& 6 hours or above & 6 & 2.0 & 2.0 & 100.0 \\
\multicolumn{1}{c}{ Total } & 300 & 100.0 & 100.0 & \\
\hline
\end{tabular}

Table 4. Students' time spending on Laptop for watching movies for playing games.

\begin{tabular}{cccccc}
\hline & & Frequency & Percent & Valid Percent & Cumulative Percent \\
\hline \multirow{4}{*}{ Valid } & 1 hour or less & 218 & 72.7 & 72.7 & 72.7 \\
& $1-2$ hours & 50 & 16.7 & 16.7 & 89.3 \\
& $2-4$ hours & 32 & 10.7 & 10.7 & 100.0 \\
& Total & 300 & 100.0 & 100.0 & \\
\hline
\end{tabular}

Table 5. Students' time spending on laptop for watching movies for making your presentations and assignments.

\begin{tabular}{cccccc}
\hline \multicolumn{5}{c}{ Making your presentations and assignments i.e. for your study related work } \\
\hline & Frequency & Percent & Valid Percent & Cumulative Percent \\
\hline \multirow{4}{*}{1 hour or less } & 39 & 13.0 & 13.0 & 13.0 \\
& $1-2$ hours & 81 & 27.0 & 27.0 & 40.0 \\
\multirow{3}{*}{ Valid } & $2-4$ hours & 83 & 27.7 & 27.7 & 67.7 \\
& $4-6$ hours & 39 & 13.0 & 13.0 & 80.7 \\
& 6 hours or above & 58 & 19.3 & 19.3 & 100.0 \\
\hline & Total & 300 & 100.0 & 100.0 & \\
\hline
\end{tabular}

Table 6. Regression analysis for NBS (Model 1).

\begin{tabular}{|c|c|c|c|c|c|c|}
\hline \multicolumn{7}{|c|}{ Coefficients $^{\mathrm{a}}$} \\
\hline & \multirow[t]{2}{*}{ Model 1} & \multicolumn{2}{|c|}{$\begin{array}{l}\text { Unstandardized } \\
\text { Coefficients }\end{array}$} & \multirow{2}{*}{$\begin{array}{c}\text { Standardized } \\
\text { Coefficients }\end{array}$} & \multirow[t]{2}{*}{$\mathrm{t}$} & \multirow[t]{2}{*}{ Sig. } \\
\hline & & B & Std. Error & & & \\
\hline \multirow{2}{*}{1} & (Constant) & 25.804 & 1.727 & & 14.944 & 0.000 \\
\hline & Need-Based Scholarship (NBS) & 7.247 & 0.057 & 0.248 & 2.575 & 0.000 \\
\hline
\end{tabular}

a. Dependent variable: Student academic performance.

HEC need-based scholarship and student academic performance because the $\mathrm{P}$-value is less than the required $1 \%-5 \%$ level and the model explains $\left(\mathrm{R}^{2}=\right.$ $24.8 \%$ ) variance in the dependent variable which is quite good in such type of studies. Our results indicate that there is a positive and significant relationship 
between HEC need-based scholarship and student academic performance. The overall model is fit for getting insights and recommendations for policymaking. The significance value is 0.000 which represents a high level of importance and confidence in data. The need-based scholarship adds more value to the students' academic performance in the Khyber Pakhtunkhwa province of Pakistan. It implies that the government of Pakistan should continue and strengthen the program for a better and brighter future of the students. Higher the scholarships will give higher results in the far lung areas of Pakistan.

\subsubsection{Prime Minister Laptop Scheme and Students' Education Performance in Short and Long Term Results}

Table 7 expresses that there is a positive and significant relationship between the Prime Minister Laptop Scheme and student academic performance because the significance value is less than the $1 \%$ significance value. The variance that is explained $\left(R^{2}=0.372\right)$ almost $37.2 \%$ is also quite sound for the overall model. The independent variable (PMLS) has a sure positive impact on the academic performance of students. The study's results indicate that the linear regression analysis is very significant for Prime Minister Laptop Scheme because it increases the students' academic performance. The results signify the contribution of the laptop schemes that it adds to the academic well-being of the students and is very important for the tech-oriented future of the students. Upon asking the respondents, the researcher came to the conclusion that the laptop schemes have increased the focus of students from mere entertainment to the productive usages of the systems. These results recommend the authority to be very cautious in the sustainability of the said program as it can strengthen the well-utilizations of the laptop.

\section{Discussion and Conclusion}

This study was solely motivated by the socio-economic investments to investigate the worth and effectiveness of conditional cash transfers to students (HEC Need-based Scholarship and Prime minister laptop scheme) in the underdeveloped areas of Khyber Pakhtunkhwa province, Pakistan. The study finds very interesting results that are worth considering in policy formulations by Higher Education Commission and other regulatory bodies. The first CCT i.e., HEC need-based scholarship was found very helpful in getting high enrollment, thus

Table 7. Regression analysis for PMLS (Model 2).

\begin{tabular}{|c|c|c|c|c|c|c|}
\hline \multicolumn{7}{|c|}{ Coefficients $^{\mathrm{a}}$} \\
\hline & \multirow[t]{2}{*}{ Model 2} & \multicolumn{2}{|c|}{$\begin{array}{l}\text { Unstandardized } \\
\text { Coefficients }\end{array}$} & \multirow{2}{*}{$\begin{array}{c}\begin{array}{c}\text { Standardized } \\
\text { Coefficients }\end{array} \\
\text { Beta }\end{array}$} & \multirow[t]{2}{*}{$\mathrm{t}$} & \multirow[t]{2}{*}{ Sig. } \\
\hline & & B & Std. Error & & & \\
\hline \multirow{2}{*}{1} & (Constant) & 30.263 & 0.633 & & 12.841 & 0.000 \\
\hline & Prime Minister Laptop Scheme (PMLS) & 6.283 & 0.220 & 0.372 & 4.036 & 0.000 \\
\hline
\end{tabular}

a. Dependent variable: Student academic performance. 
increasing the ratio of higher education in Pakistan. The less-developed regions and the students over there were truly supported by the scheme. They were on the verge of leaving their higher education but the CCT attracted them and now they are pleasantly continuing their education in the higher education institutions and universities.

The study also found the productivity and effectiveness of the Prime minister laptop scheme in terms of their usages. From our analysis, we got that most of the students spend their huge time on learning and educational purposes. Only one hour is being spent for watching movies or other videos by the students who got laptops from the government. The study further found that almost one hour of the students' time is being spent on video games. The devotion of students' time to social media was reported to be high as some students spend 5 - 6 hours using social networking sites. Besides the educational purposes, the study also got the results that the PM laptops are used for career counseling, career development and finding jobs in various organizations local as well as abroad.

In our survey, different questions have been asked in order to check the productivity and achievement of HEC need-based scholarship and Government laptop scheme for the long run as well short run. Some students viewed that laptops have not helped them in their academic and professional skills. Moreover, the majority of the students who got the laptop through the Government laptop program agree that they are getting into the technology-orientation by using these laptops. On the flip side, some outcomes were not encouraging that showed low students' productivity in terms of academics, education or technology orientation.

This research concludes that conditional cash transfer (CCTs) plans are effective in the settings in which preliminary enrollment and presence situations are comparatively weak and as a result, specifically useful in enhancing the educational results of the youth. This is also advisable to set some criteria for the awardee students to use the CCTs for their better education and career development. Especially, being war-trodden areas in Pakistan, such plans may be continued with the help of international donor agencies given that these are positively and productively used by the students.

Some strategies and alternatives policies are also needed for the general development in the higher education system with regard to enrollment and admission, fairness and quality. The target of these CCT programs such as HEC need-based scholarship and Prime Minister's Youth Laptop scheme is incoherent with the objectives of the CCT plan as the levels of poverty are not consistent across several areas in Pakistan. This study found that the Prime Minister grants to youth is very significant and assists in the proliferation of higher education in the less developed areas of Pakistan. The laptop scheme is also very fruitful and has a significant impact on students' academic development.

\section{Theoretical and Practical Implications}

This research adds to the theoretical aspects that such type of conditional cash 
transfers is really helpful for the local community and it has certain impacts on the growth and enhancement of higher education in Pakistan. This phenomenon is worth researching for academicians in the public sector education. Such schemes need to be debated by the research communities to further improve its mechanism, structure, and implementation so that they can yield more. Social investments may spark more studies to be pursued in other areas of social groups.

The schemes are very much appealing for practitioners and this study provides policy recommendations for the regulators, HEC Pakistan and other concerned to make the schemes more effective in terms of enrollment and target-achieving. The concerned universities and higher education institutions also need to effectively execute the plans so that the government targets can be sustainably achieved.

\section{Limitation and Future Research Suggestions}

This study has a few limitations that can be covered in future studies. First, the study is limited in terms of its findings as it focused on the context of Pakistan. The results are, therefore, worth analyzing before applying to the practices in other settings. Secondly, we used a questionnaire-based primary data that were collected from a few districts of Khyber Pakhtunkhwa. This might limit the generalizability of the study to the whole country or other countries. Future studies can give more focus to a large set of data or may use the mixed methodology to reach at more conclusive results. Further, new variables may be added to make the theoretical model more comprehensive. There are some other programs from the government side which need researchers' lens to study them in full ins and outs. For example, the "EHSAAS Undergraduate Scholarship Program" has currently been launched for the poor youth of Pakistan. The government of $\mathrm{Pa}$ kistan is also giving subsidized loans to the youth of tribal areas which is also a sort of social investment and a worthwhile research endeavor for new studies.

\section{Conflicts of Interest}

The authors declare no conflicts of interest regarding the publication of this paper.

\section{References}

[1] Baum, S., Ma, J. and Payea, K. (2013) Education Pays 2013. The College Board, New York.

[2] Koh, K.H., Tan, C. and Ng, P.T. (2012) Creating Thinking Schools through Authentic Assessment: The Case in Singapore. Educational Assessment, Evaluation and Accountability, 24, 135-149. https://doi.org/10.1007/s11092-011-9138-y

[3] Barrera-Osorio, F., Linden, L.L. and Saavedra, J. (2017) Medium- and Long-Term Educational Consequences of Alternative Conditional Cash Transfer Designs: Experimental Evidence from Colombia. National Bureau of Economic Research, Cambridge. https://doi.org/10.3386/w23275 
[4] Kena, G., Aud, S., Johnson, F., Wang, X.L., Zhang, J.J., Rathbun, A., Kristapovich, P., et al. (2014) The Condition of Education 2014. NCES 2014-083. National Center for Education Statistics, Washington DC.

[5] Thomson, P. (2015) Poverty and Education. Paper Presented at the FORUM: For Promoting 3-19 Comprehensive Education.

[6] Covarrubias, K., Davis, B. and Winters, P. (2012) From Protection to Production: Productive Impacts of the Malawi Social Cash Transfer Scheme. Journal of Development Effectiveness, 4, 50-77. https://doi.org/10.1080/19439342.2011.641995

[7] Del Carpio, X.V., Loayza, N.V. and Wada, T. (2016) The Impact of Conditional Cash Transfers on the Amount and Type of Child Labor. World Development, 80, 33-47. https://doi.org/10.1016/j.worlddev.2015.11.013

[8] Slater, R. (2011) Cash Transfers, Social Protection and Poverty Reduction. International Journal of Social Welfare, 20, 250-259. https://doi.org/10.1111/j.1468-2397.2011.00801.x

[9] Ahmed, K. and Long, W. (2012) Environmental Kuznets Curve and Pakistan: An Empirical Analysis. Procedia Economics and Finance, 1, 4-13. https://doi.org/10.1016/S2212-5671(12)00003-2

[10] Afzal, M., Malik, M.E., Begum, I., Sarwar, K. and Fatima, H. (2016) Relationship among Education, Poverty and Economic Growth in Pakistan: An Econometric Analysis. Journal of Elementary Education, 22, 23-45.

[11] Shah, F.T. (2013) Service Quality and Customer Satisfaction in Higher Education in Pakistan. Journal of Quality and technology Management, 9, 73-89.

[12] Yousaf, M., Ihsan, F. and Ellahi, A. (2016) Exploring the Impact of Good Governance on Citizens' Trust in Pakistan. Government Information Quarterly, 33, 200-209. https://doi.org/10.1016/j.giq.2015.06.001

[13] Manley, J. and Slavchevska, V. (2016) Are Cash Transfers the Answer for Children in Sub-Saharan Africa? A Literature Review.

[14] García, S. and Saavedra, J.E. (2017) Educational Impacts and Cost-Effectiveness of Conditional Cash Transfer Programs in Developing Countries: A Meta-Analysis. Review of Educational Research, 87, 921-965. https://doi.org/10.3102/0034654317723008

[15] Attanasio, O.P., Oppedisano, V. and Vera-Hernández, M. (2015) Should Cash Transfers Be Conditional? Conditionality, Preventive Care, and Health Outcomes. American Economic Journal: Applied Economics, 7, 35-52. https://doi.org/10.1257/app.20130126

[16] Benhassine, N., Devoto, F., Duflo, E., Dupas, P. and Pouliquen, V. (2015) Turning a Shove into a Nudge? A "Labeled Cash Transfer" for Education. American Economic Journal: Economic Policy, 7, 86-125. https://doi.org/10.1257/pol.20130225

[17] De La, O. and Ana, L. (2013) Do Conditional Cash Transfers Affect Electoral Behavior? Evidence from a Randomized Experiment in Mexico. American Journal of Political Science, 57, 1-14. https://doi.org/10.1111/j.1540-5907.2012.00617.x

[18] Baird, S., Ferreira, F.H.G., Özler, B. and Woolcock, M. (2013) Relative Effectiveness of Conditional and Unconditional Cash Transfers for Schooling Outcomes in Developing Countries: A Systematic Review. Campbell Systematic Reviews, 9, 1-124. https://doi.org/10.4073/csr.2013.8

[19] Roelen, K. (2014) Sticks or Carrots? Conditional Cash Transfers and Their Effect on Child Abuse and Neglect. Child Abuse \& Neglect, 38, 372-382.

https://doi.org/10.1016/j.chiabu.2014.01.014 
[20] Zibagwe, S., Nduna, T. and Dafuleya, G. (2013) Are Social Protection Programmes Child-Sensitive? Development Southern Africa, 30, 111-120. https://doi.org/10.1080/0376835X.2012.756100

[21] De Brauw, A. and Hoddinott, J. (2011) Must Conditional Cash Transfer Programs Be Conditioned to Be Effective? The Impact of Conditioning Transfers on School Enrollment in Mexico. Journal of Development Economics, 96, 359-370. https://doi.org/10.1016/j.jdeveco.2010.08.014

[22] Pellerano, L. and Barca, V. (2017) The Conditions for Conditionality in Cash Transfers: Does One Size Fit All? In: What Works for Africa's Poorest. Programmes and Policies for the Extreme Poor, Practical Action Publishing, London, 223-242. https://doi.org/10.3362/9781780448435.013

[23] Saavedra, J.E. and García, S. (2012) Impacts of Conditional Cash Transfer Programs on Educational Outcomes in Developing Countries: A Meta-Analysis. RAND Labor and Population Working Paper Series, WR-921-1. https://doi.org/10.7249/WR921-1

[24] Parajuli, D., Acharya, G., Chaudhury, N. and Thapa, B.B. (2012) Impact of Social Fund on the Welfare of Rural Households: Evidence from the Nepal Poverty Alleviation Fund. The World Bank, Washington DC.

https://doi.org/10.1596/1813-9450-6042

[25] Friedman, W., Kremer, M., Miguel, E. and Thornton, R. (2016) Education as Liberation? Economica, 83, 1-30. https://doi.org/10.1111/ecca.12168

[26] Dubois, P., De Janvry, A. and Sadoulet, E. (2012) Effects on School Enrollment and Performance of a Conditional Cash Transfer Program in Mexico. Journal of Labor Economics, 30, 555-589. https://doi.org/10.1086/664928

[27] Ham, A. (2014) The Impact of Conditional Cash Transfers on Educational Inequality of Opportunity. Latin American Research Review, 49, 153-175. https://doi.org/10.1353/lar.2014.0049

[28] Li, J. (2016) An Assessment of the Medium Term Impacts of a Honduran Conditional Cash Transfer Experiment on Education and Fertility.

[29] Benedetti, F., Ibarrarán, P. and McEwan, P.J. (2016) Do Education and Health Conditions Matter in a Large Cash Transfer? Evidence from a Honduran Experiment. Economic Development and Cultural Change, 64, 759-793. https://doi.org/10.1086/686583

[30] Barham, T., Macours, K. and Maluccio, J.A. (2018) Experimental Evidence of Exposure to a Conditional Cash Transfer during Early Teenage Years: Young Women's Fertility and Labor Market Outcomes. CEPR Discussion Papers.

[31] Baird, S., McIntosh, C. and Özler, B. (2011) Cash or Condition? Evidence from a Cash Transfer Experiment. The Quarterly Journal of Economics, 126, 1709-1753. https://doi.org/10.1093/qje/qjr032

[32] Memon, A.R. and Awan, M.M. (2017) Higher Education Needs More Improvement: The Case of Pakistan. Journal of Pakistan Medical Association, 67, 821.

[33] Qazi, W., Raza, S.A. and Sharif, A. (2017) Higher Education Development and Unemployment in Pakistan: Evidence from Structural Break Testing. Global Business Review, 18, 1089-1110. https://doi.org/10.1177/0972150917710344

[34] Tahir, M.W., Kauser, R., Bury, M. and Bhatti, J.S. (2018) "Individually-Led" or "Female-Male Partnership" Models for Entrepreneurship with the BISP Support: The Story of Women's Financial and Social Empowerment from Pakistan. Women's Studies International Forum, 68, 1-10. https://doi.org/10.1016/j.wsif.2018.01.011

[35] Nishtar, S., Boerma, T., Amjad, S., Alam, A.Y., Khalid, F., ul Haq, I. and Mirza, Y.A. 
(2013) Pakistan's Health System: Performance and Prospects after the 18th Constitutional Amendment. The Lancet, 381, 2193-2206.

https://doi.org/10.1016/S0140-6736(13)60019-7

[36] Ham, A. and Michelson, H.C. (2018) Does the Form of Delivering Incentives in Conditional Cash Transfers Matter over a Decade Later? Journal of Development Economics, 134, 96-108. https://doi.org/10.1016/j.jdeveco.2018.05.007

[37] Sultana, M. and Haque, M.S. (2018) The Cause of Low Enrolment of Females in Secondary Education: A Comparative Study between Bangladesh and Pakistan. International Journal of Development Research, 8, 23110-23116.

[38] Siddiqui, M.A. and Tagar, H.K. (2018) Significance of Literacy in Inclusive Growth and Coherent Development Planning to Deal with Challenge of Quality Education for All in Pakistan. Archives of Business Research, 6, 132-139.

https://doi.org/10.14738/abr.611.5560

[39] Damaiyanti, M. and Fitriani, D.R. (2018) The Relation of Educational Level, Academic Achievement (GPA) and Depression among Public School Adolescent. Indonesian Journal of Nursing Practices, 1, 83-90. https://doi.org/10.18196/ijnp.1365 